\title{
IMPORTANCE OF LUNAR AND TEMPORAL CONDITIONS FOR SPOTLIGHT SURVEYS OF ADULT BLACK-FOOTED FERRETS
}

\author{
David A. Eads ${ }^{1,3}$, David S. Jachowski ${ }^{1}$, Joshua J. Millspaugh ${ }^{1}$, and Dean E. Biggins ${ }^{2}$
}

\begin{abstract}
Black-footed ferrets (Mustela nigripes) spend most daylight hours underground in prairie dog (Cynomys) burrows and exhibit aboveground movements primarily at night. Moonlight can influence the activity patterns of ferrets and, consequently, might influence the efficiency of spotlight surveys used by biologists to monitor ferret populations. We related detection of adult ferrets during postbreeding spotlight surveys to lunar and temporal conditions. We most frequently located ferrets during surveys in which the moon breached the horizon. The data suggested intersexual differences in response to moonlight. We located male ferrets most frequently during nights with greater moon illumination, but we did not detect a correlation between moon illumination and spotlight detection of female ferrets. In general, moonlight could facilitate aboveground navigation by ferrets. However, it seems activity under bright moonlight could be costly for female ferrets while they raise young. Detection of ferrets also varied among months. We detected female ferrets most frequently in August-September, when mothers increase hunting efforts to acquire prey for growing offspring (kits). Detection of adult female ferrets declined in October, when kits were likely independent of their mother. We located male ferrets most frequently in September-October, when males might increase activity to monitor female ferrets and male competitors. Consideration of lunar and temporal influences and standardization of postbreeding surveys could enhance site-specific assessment of reintroduction success and across-site assessment of species recovery progress. We suggest that postbreeding surveys for ferrets should be enhanced by concentrating efforts in August-September during moonlit nights when the moon is above the horizon.
\end{abstract}

RESUMEN.-Los hurones de patas negras (Mustela nigripes) pasan la mayor parte de las horas del día debajo de la tierra en madrigueras de perros llaneros (Cynomys). La actividad que exhiben sobre el suelo principalmente ocurre de noche. La luz de la luna puede influenciar los patrones de actividad de los hurones y, como consecuencia, podría afectar la eficiencia de las revisiones basadas en reflectores que usan los biólogos para monitorear las poblaciones de hurones. Examinamos la relación entre la probabilidad de detección de hurones adultos durante los monitoreos con reflectores y que fueron realizados después del periodo de apareamiento con las condiciones lunares y temporales. Encontramos hurones más a menudo durante los monitoreos realizados cuando la luna salió sobre el horizonte. Sin embargo, los datos sugirieron diferencias entre sexos en la respuesta a la luz de la luna. Encontramos hurones machos más frecuentemente durante las noches en las que había más luz lunar; sin embargo, no detectamos una correlación entre la iluminación lunar y la detección de hembras con el uso de reflectores. En general, la luz de la luna podría facilitar la orientación de los hurones sobre el suelo, pero parece ser que la actividad bajo una resplandeciente luz lunar podría ser costosa para los hurones hembras que tienen crías. La detección de hurones también varió dependiendo del mes. Detectamos hurones hembras más frecuentemente en agosto y septiembre, cuando las madres aumentan sus esfuerzos de caza para obtener presas para sus crías en desarrollo (kits). La detección de los hurones hembras adultas disminuyó en octubre, cuando muy posiblemente las crías lograron independizarse de sus madres. Ubicamos con mayor frecuencia hurones machos en septiembre y octubre, que es cuando tal vez los machos aumentan su actividad para vigilar a las hembras y a posibles machos competidores. La consideración de los efectos lunares y temporales así como la estandarización de monitoreos después del apareamiento podrían mejorar las evaluaciones en sitios particulares para medir el éxito de las reintroducciones y también las evaluaciones entre sitios del progreso en la recuperación de la especie. Sugerimos que deben mejorarse los monitoreos de los hurones después de su periodo de apareamiento concentrando los esfuerzos en agosto y septiembre durante las noches cuando hay luz de la luna y ésta se encuentra por encima del horizonte.

Nocturnal predators might hunt more efficiently and be most active under certain lunar conditions, suggesting the moon is particularly important in nighttime predator-prey interactions. Indeed, risk of predation can depend on the position of the moon (above or below the horizon) and the proportion of the moon illuminated (Lima and Dill 1990, Caro 2005). Not surprisingly, lunar conditions influence activity patterns of many prey species. However, responses vary among and within species (e.g., Lockard and Owings 1974, Kotler 1984). Some

${ }^{1}$ Department of Fisheries and Wildlife Sciences, University of Missouri, 302 Natural Resources Building, Columbia, MO 65211-7240.

${ }^{2}$ U.S. Geological Survey, Fort Collins Science Center, 2150 Centre Avenue, Building C, Fort Collins, CO 80526-8118.

${ }^{3}$ Present address: Graduate Degree Program in Ecology, Department of Biology, Colorado State University, Fort Collins, CO 80523-1878. E-mail: david.eads@colostate.edı 
prey species primarily reduce activity under bright moonlight (Kotler 1984, Brown et al. 1988, Kotler et al. 1991, Topping et al. 1999, Ylönen and Brown 2007), while others increase activity under moonlight (Bearder et al. 2002, Biebouw and Blumstein 2003) or respond variably to moonlight, for instance, by season (Lockard and Owings 1974). Thus, it can be difficult to predict whether a species increases or decreases activity under moonlight or whether the species is relatively insensitive to lunar conditions (Prugh and Brashares 2010).

Knowledge of the activity patterns of a focal species under differing lunar conditions is of behavioral interest and conservation importance. For example, such knowledge can assist in optimizing efforts to monitor populations of endangered black-footed ferrets (Mustela nigripes), which are primarily nocturnal carnivores. Spotlight surveys are the most commonly used technique to monitor ferrets (Biggins et al. 2006a). Surveyors locate ferrets via eyeshine and identify individuals using PIT tags (Fagerstone and Johns 1987, Biggins et al. 2006a) and dye marks (e.g., Grenier et al. 2009, Jachowski et al. 2010, Eads et al. 2011a, 2011b), thereby tallying numbers of located ferrets. These data are used to estimate population size (Forrest et al. 1988, Grenier et al. 2009), information used to assess recovery success (sensu U.S. Fish and Wildlife Service 2006). However, the timing and effort spent accomplishing spotlight surveys vary among sites, which increases the difficulty of comparing population sizes among sites and, thus, assessing success of the ferret reintroduction program.

To facilitate studies and conservation of the ferret, an increased understanding of factors affecting detection of ferrets is needed (Biggins et al. 2006a). Ferrets spend most nighttime hours underground in prairie dog (Cynomys) burrows (Biggins 2000). For population estimation, it is important to conduct spotlight surveys when aboveground activity of ferrets and, therefore, detection are most likely. Like other species, ferrets vary the timing of their aboveground movements according to lunar conditions. In Shirley Basin, Wyoming, 20 released ferrets, radio-tracked in September-December 1991, exhibited an increased number of activity bouts during "moonlit" nights (>1.5 h with moonlight) relative to "dark" ( $<1.5 \mathrm{~h}$ with moonlight) and "mixed" nights (Biggins et al. 2011). This suggests that ferrets are more likely to be active aboveground and detected via spotlight during moonlit nights. However, this contention remains unverified via spotlight data.

Monthly variation in activity would also be important in scheduling spotlight surveys for ferrets. Indeed, ferrets exhibit differing rates of activity among months (e.g., Biggins et al. 1986), altering their activities relative to changes in prey requirements and, for adult females, the needs of kits (Jachowski 2007a). Thus, spotlight detection of ferrets likely differs among months, perhaps between sexes. Monthly variation in spotlight detection has been discussed for ferret populations (Biggins et al. 2006a) but not quantified via repeated spotlight searches for individual adult ferrets.

In this study, we investigated 3 hypotheses: spotlight detection of ferrets (1) is greatest during nights in which the moon breaches the horizon, (2) is greatest during moonlit nights with bright moonlight, and (3) varies among months and by sex. To investigate these hypotheses, we related spotlight detection of adult ferrets to survey-specific lunar and temporal conditions in the Conata Basin, South Dakota. In addition to investigating ferret ecology, we aimed to develop models to describe spotlight detection of ferrets during the postbreeding season (JuneOctober). If they predict detection accurately, such models would aid in increasing detection of ferrets and, consequently, would facilitate efforts to estimate population sizes and assess recovery progress for the black-footed ferret.

\section{StUdy AREAS}

The Conata Basin is a 29,000-ha, mixed-grass prairie complex in southwestern South Dakota. We monitored adult, wild-born ferrets inhabiting 2 black-tailed prairie dog (Cynomys ludovicianus) colonies, herein termed SC24 (227 ha) and SC07 (452 ha). The colonies were primarily on the Buffalo Gap National Grassland, which is managed by the USDA Forest Service. These grasslands are predominantly covered by western wheatgrass (Pascopyrum smithii), blue grama (Bouteloua gracilis), and buffalograss (Buchloe dactyloides). Each colony was bordered by badland buttes and seasonal drainages but was characterized by relatively flat terrain and low vegetation (various forbs) within colony boundaries.

Ferrets were first reintroduced to these colonies in 1997 (Livieri 2006). During our 
study, 7 ferrets inhabited SC24 in 2005 (17 June14 October) and 2006 (13 June-31 October), 11 ferrets inhabited SC07 in 2007 (13 June-10 October), and 14 ferrets inhabited SCO7 in 2008 (11 June-27 September). For these respective years, female-to-male ratios were $4: 3$ and 5:2 on SC24 (Jachowski 2007b) and 8:3 and 9:5 on SC07 (Eads 2009).

\section{Methods \\ Spotlight Surveys}

We searched for adult ferrets (kit data not included) via spotlight surveys (Clark et al. 1984, Campbell et al. 1985, Biggins et al. 2006a) on nearly consecutive nights. We limited our data to surveys accomplished between midnight and 06:00 (MDT); survey effort was often sporadic during other periods. Searchers drove an all-terrain or $4 \mathrm{WD}$ vehicle $8-16 \mathrm{~km} \cdot \mathrm{h}^{-1}$ (completed 6-10 times per survey) on survey routes established to maximize coverage of the study colonies while minimizing overlap. We used high-intensity $240 \mathrm{BLITZ}^{\mathrm{TM}}$ Lightforce spotlights (Lightforce Professional Lighting Systems, Australia) to detect ferret eyeshine. We limited disturbance of located ferrets by minimizing spotlight illumination upon observation.

We identified ferrets via PIT tags (AVID Microchip ID Systems, Folsom, LA). A PITreader loop antenna circumscribed an occupied burrow opening and acquired animal-specific identification numbers as the tagged ferret emerged from the burrow through the antenna (Fagerstone and Johns 1987, Biggins et al. 2006a). We identified nontagged ferrets via dyemarks (Grenier et al. 2009, Jachowski et al. 2010, Eads et al. 2011a, 2011b). Thus, ferrets were identified to individual and sex. All females produced and raised kits.

We limited our data to ferrets consistently located and identified throughout each field season. Specifically, we limited the sample to ferrets located $\geq 30$ times. Ferrets located $<30$ times might have been transients or might have emigrated or died during the periods of study, suggesting the animals might not have been available for detection during some or many surveys. Ferrets located $\geq 30$ times might have also emigrated or died later in the field season, but the likelihood of either outcome is lower for these ferrets than for ferrets located $<30$ times. The final sample included many of the monitored adult ferrets $(71.43 \%$ in $2005,42.86 \%$ in
2006 at SC24; $91.67 \%$ in 2007, $71.43 \%$ in 2008 at $\mathrm{SC} 07$ ), indicating high probabilities of detection at each site and availability of these ferrets for spotlight detection throughout the majority (or all) of each field season.

\section{Data Analyses}

We related the spotlight data to month, presence or absence of moonlight, and moon illumination using generalized linear mixed models (GLMMs; McCullagh and Nelder 1989) via the "lme4" package in Program R version 2.11.1 (R Development Core Team 2010). In each GLMM, we defined individual ferrets as random effects. This approach is useful with nested data, such as our spotlight data with repeated measures for individual ferrets; GLMMs can account for potential interdependence (autocorrelation) of repeated measures for individual animals. GLMMs can provide different (random) intercepts, slopes, or intercepts and slopes for each individual ferret (Gelman and Hill 2007, Zuur et al. 2009). In our modeling exercise, Akaike's information criteria (AIC; Burnham and Anderson 2002) indicated greater support for models with different intercepts. Thus, here we only discuss results for GLMMs that estimated unique intercepts for each ferret.

We first related the spotlight data to month and presence or absence of moonlight. We denoted individual ferrets as located (1) or not located (0) during each survey. Thus, the response variable was binomial (detection or nondetection) rather than numerical (numbers of detections). We assumed that ferrets not detected during a survey were alive and within the area surveyed because of cumulative detections. We classified surveys according to the presence or absence of moonlight as moon surveys (above-horizon time of moon $>0 \mathrm{~h}$ ) or non-moon surveys using United States Naval Observatory (USNO) estimates of moonrise and moonset at Interior, South Dakota, a town $26 \mathrm{~km}$ from the study colonies. Nightly cloud cover was often minimal. The moon-survey variable was included to investigate if presence of the moon (i.e., moon above the horizon) was important in detecting ferrets.

We used an information theoretic approach to model selection using AIC (Burnham and Anderson 2002). This exercise included linear $(x)$, quadratic $\left(x^{2}+x\right)$, and pseudothreshold (e.g., $\log [x+0.50]+x$ ) forms of month (Franklin et al. 2000) and a linear effect of the 
moon-survey binomial variable. In addition to these covariates, we included sex as a main effect, and considered condition $\times$ sex interactions between moon-survey and sex (in case the effect of moon-survey varied between sexes) and between month and sex (in case monthly patterns of detection varied between sexes). We fit all possible models. If an interaction was included in a GLMM, then both terms were included as main effects (McCullagh and Nelder 1989). We considered models within 2 AIC units as competing (Burnham and Anderson 2002). As outlined in the results, condition $\times$ sex interactions were supported, justifying separate assessments by sex. For each sex, we investigated all possible GLMMs and interpreted the most supported model.

We conducted a separate, GLMM assessment for moon illumination. The previous GLMMs suggested that if the moon breached the horizon during a survey (constituting a moon survey), ferrets of both sexes were more likely to be detected. So what is the likelihood of detecting a ferret during a moon survey with a particular amount of moonlight? For the moon illumination investigation, we limited data to those collected during moon surveys. Again, for each survey, we denoted ferrets as detected or not detected (response variable). This restricted dataset included ferrets located $\geq 30$ times during an entire field season but not necessarily located $\geq 30$ times during moon surveys. We classified each survey with a respective moon illumination score derived as USNO estimates of the fraction of the moon illuminated over Interior, South Dakota, each survey night. We investigated linear and nonlinear forms of moon illumination (forms above), a sex main effect, and a condition $\times$ sex interaction. We investigated all possible models. A condition $\times$ sex interaction was supported, again suggesting separate assessments by sex. We investigated all possible sex-specific GLMMs and interpreted the most supported model for each sex.

In each modeling exercise, we assessed statistical significance of the most supported sexspecific models relative to intercept-only models using deviance ratio tests $(\alpha=0.05$; McCullagh and Nelder 1989). In addition, we evaluated the predictive capabilities of the most supported GLMMs using $k$-fold cross-validation, a type of internal model validation. For each GLMM, we divided the data into 5 random subsets, each composed of training and testing sets (80:20 ratios of animal samples). We iteratively withheld one subset, fit the most supported model using the training data, and used estimated coefficients to predict values for the training and testing data sets. We separated predicted values into 32 equal-interval bins scaled between the minimum and maximum scores. In all cases, the final bin contained no predicted values; thus, we simplified to 31 bins. We used Spearman's rank correlation to compare the frequencies by bin of predicted values for the test data of each GLMM to the frequencies by bin of predicted values for the training data of respective GLMMs. For a specific GLMM, significant, positive Spearman's rank correlations from $k$-fold cross-validation would indicate consistency in model fit with the differing random subsets of data, thus suggesting good model performance and an increased probability that the model predicts the phenomenon of interest (spotlight detection of ferrets).

\section{RESUlts}

The overall data set included 1050 detections of 14 adult female and 10 adult male ferrets collected during 402 survey nights (1707 nondetections). We collected an average of 36.53 $(\mathrm{SD}=5.92)$ observations per adult female and $35.75(\mathrm{SD}=7.01)$ observations per adult male. We monitored 1 adult male and 3 adult female ferrets during 2 consecutive years. As outlined above, in model development, the repeatedmeasures GLMM accounted for potential interdependence of these samples and repeated measures for individual ferrets.

In the first modeling exercise, the 2 most supported GLMMs $(\Delta \mathrm{AIC}=1.97)$ included the quadratic month effect, the main effects for sex and moon-survey, the interaction between sex and the quadratic month effect, and the interaction between sex and moon-survey (Table 1$)$. The condition $\times$ sex interactions suggested separate assessments by sex, so we separated the analysis by sex. For each sex, we interpreted the model with the lowest AIC value (Table 1). Deviance ratio tests indicated significance of the female $($ ratio $=83.54, \mathrm{df}=2, P$ $<0.001$ ) and male (ratio $=37.22, \mathrm{df}=2, P<$ $0.001)$ GLMMs, and cross-validation indicated good performance of each GLMM for all $k$-fold sets (all $r_{\mathrm{s}}>0.97$ and $P<0.001$ ). Estimated variances for the random intercepts $(\hat{d})$ were 
TABLE 1. The first modeling exercise, which related spotlight detection of adult black-footed ferrets (Mustela nigripes) to month and presence/absence of moonlight (Moon-survey) during spotlight surveys. Models are generalized linear mixed effects models. The exercise involved investigation of models for the sexes combined using Akaike's information criterion (AIC) and, given support for interactions between sex and the main effects, separation of the analysis by sex and selection of sex-specific models that reduced AIC most. We present models within 5 AIC units of the most supported model and the intercept-only models.

\begin{tabular}{|c|c|c|c|}
\hline Sex & Model structure & $\mathrm{AIC}$ & $\Delta \mathrm{AIC}$ \\
\hline \multirow[t]{4}{*}{ Both } & Month + Month $^{2}+$ Moon-survey + Sex $+\left(\right.$ Month + Month $\left.^{2}\right) \times$ Sex & 3557.77 & 0 \\
\hline & $\begin{array}{l}\text { Month }+ \text { Month }{ }^{2}+\text { Moon-survey }+ \text { Sex }+\left(\text { Month }+ \text { Month }^{2}\right) \\
\quad \times \text { Sex }+ \text { Moon-survey } \times \text { Sex }\end{array}$ & 3559.74 & 1.97 \\
\hline & Month + Month $^{2}+$ Sex $+\left(\right.$ Month + Month $\left.^{2}\right) \times$ Sex & 3561.86 & 4.09 \\
\hline & Intercept-only & 3667.10 & 109.33 \\
\hline \multirow[t]{5}{*}{ Females } & Month + Month ${ }^{2}+$ Moon-survey & 2067.83 & 0 \\
\hline & $\log ($ Month +0.05$)+$ Month + Moon-survey & 2068.77 & 0.94 \\
\hline & Month + Month ${ }^{2}$ & 2069.78 & 1.95 \\
\hline & $\log ($ Month +0.05$)+$ Month & 2070.63 & 2.80 \\
\hline & Intercept-only & 2145.37 & 77.54 \\
\hline \multirow[t]{4}{*}{ Males } & Month + Month ${ }^{2}+$ Moon-survey & 1492.87 & 0 \\
\hline & $\log ($ Month +0.05$)+$ Month + Moon-survey & 1493.01 & 0.14 \\
\hline & Month + Month $^{2}$ & 1494.03 & 1.16 \\
\hline & Intercept-only & 1525.08 & 32.21 \\
\hline
\end{tabular}

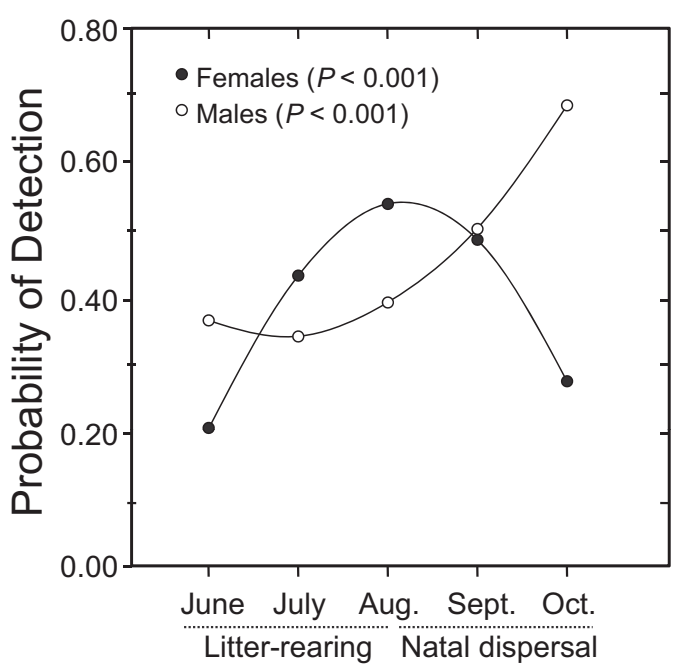

Fig. 1. Estimated quadratic $\left(x^{2}+x\right)$ month effects from generalized linear mixed models describing the probability of detecting adult female or male black-footed ferrets (Mustela nigripes) via late-night, postbreeding spotlight surveys on 2 black-tailed prairie dog (Cynomys ludovicianus) colonies in the Conata Basin, South Dakota, 2005-2008. Estimated variances for the random intercepts were low; thus, we present fixed-effect population models for female and male ferrets from Table 2. $P$ values were derived from deviance ratio tests that compared the most supported model for a sex to an intercept-only model for that sex (see Table 1).

low (female $\hat{d}=0.02$, male $\hat{d}=0.01$ ), suggesting similar intercepts for same-sex ferrets. Therefore, we describe sex-specific GLMMs that combined the random intercepts into a population-level intercept. We increasingly detected adult female ferrets during June-August; however, detection declined in SeptemberOctober (Fig. 1). We detected adult male ferrets less frequently in July, relative to June; detection increased thereafter (Fig. 1). We located adult female and adult male ferrets most frequently during moon surveys in which the moon breached the horizon and less frequently during non-moon surveys (Table 2).

The moon illumination GLMM analysis included 781 detections during 289 moon surveys (1227 nondetections). This data set included, on average, $27.06(\mathrm{SD}=5.97)$ observations per adult female ferret and $26.75(\mathrm{SD}=4.94) \mathrm{ob}-$ servations per adult male ferret.

The most supported GLMM included the quadratic effect for moon illumination, the sex main effect, and the interaction between these variables (Table 3). We separated the analysis by sex. Again, for each sex, we interpreted the model of lowest AIC value (Table 3). Sex-specific moon-survey GLMMs suggested different influences of moon illumination on detection of male and female ferrets. Estimated variances for the random intercepts were low (female $\hat{d}=0.05$, male $\hat{d}=0.00)$, stimulating interpretation of GLMMs with the random intercepts combined into a population-level intercept. The moon-survey GLMM for males included the linear illumination effect (Table 4); a deviance ratio test indicated significance (ratio $=5.89$, $\mathrm{df}=1, P=0.024)$ and cross-validation indicated good performance for all $k$-fold sets $\left(\right.$ all $r_{\mathrm{s}}>$ 
TABLE 2. Generalized linear mixed models of the quadratic main effects of month, and linear effect of presence/ absence of moonlight (moon [1] vs. non-moon survey [0]) describing the probability of detecting adult female and male black-footed ferrets during 402 late-night, postbreeding spotlight surveys on 2 black-tailed prairie dog colonies in the Conata Basin, South Dakota, 2005-2008.

\begin{tabular}{llrrr}
\hline & Variable & \multicolumn{1}{c}{ SE } & Pr $(>|z|)$ \\
\hline Females & Intercept & -21.38 & 2.50 & $<0.001$ \\
& Month & 5.22 & 0.64 & $<0.001$ \\
& Month & -0.32 & 0.04 & $<0.001$ \\
Males & Moon-survey & 0.24 & 0.12 & 0.047 \\
& Intercept & 5.66 & 2.60 & 0.030 \\
& Month & -1.92 & 0.67 & 0.004 \\
& Month & 0.14 & 0.04 & 0.001 \\
& Moon-survey & 0.21 & 0.14 & 0.143 \\
\hline
\end{tabular}

TABLE 3. The second modeling exercise, which related spotlight detection of adult black-footed ferrets (Mustela nigripes) to moon illumination during moon surveys (i.e., spotlight surveys during which the moon breached the horizon). Models are generalized linear mixed effects models. The exercise involved investigation models for the sexes combined using Akaike's information criterion (AIC) and, given support for interactions between sex and the main effects, separation of the analysis by sex and selection of sex-specific models that reduced AIC most. We present models within 5 AIC units of the most supported model and the intercept-only models.

\begin{tabular}{|c|c|c|c|}
\hline Sex & Model structure & AIC & $\Delta \mathrm{AIC}$ \\
\hline \multirow[t]{6}{*}{ Both } & 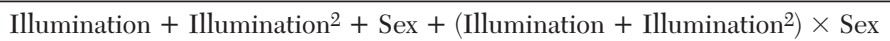 & 2681.14 & 0 \\
\hline & Illumination + Illumination ${ }^{2}$ & 2685.14 & 4.00 \\
\hline & Illumination & 2685.16 & 4.02 \\
\hline & $\log ($ Illumination +0.05$)+$ Illumination & 2685.22 & 4.08 \\
\hline & Intercept-only & 2685.98 & 4.84 \\
\hline & Illumination + Illumination $\times$ Sex & 2686.00 & 4.86 \\
\hline \multirow[t]{4}{*}{ Females } & Intercept-only & 1567.30 & 0 \\
\hline & $\log ($ Illumination +0.05$)+$ Illumination & 1567.53 & 0.23 \\
\hline & Illumination + Illumination ${ }^{2}$ & 1567.98 & 0.68 \\
\hline & Illumination & 1569.27 & 1.97 \\
\hline \multirow[t]{4}{*}{ Males } & Illumination & 1117.50 & 0 \\
\hline & $\log ($ Illumination +0.05$)+$ Illumination & 1119.45 & 1.95 \\
\hline & Illumination + Illumination ${ }^{2}$ & 1119.50 & 2.00 \\
\hline & Intercept-only & 1121.37 & 3.87 \\
\hline
\end{tabular}

TABLE 4. Generalized linear mixed models of the moon illumination $(1.00=$ full moon $)$ main effect describing the probability of detecting adult female (pseudothreshold form) and male (linear form) black-footed ferrets during 289 late-night, postbreeding spotlight surveys on 2 black-tailed prairie dog colonies in the Conata Basin, South Dakota, 2005-2008.

\begin{tabular}{llrrr}
\hline & Variable & $\beta$ & $\mathrm{SE}$ & $\operatorname{Pr}(>|z|)$ \\
\hline Females & Intercept & -1.90 & 0.76 & 0.012 \\
& Illumination & 2.55 & 1.32 & 0.053 \\
\multirow{2}{*}{ Males } & $\log ($ Illumination +0.50$) \times$ Illumination & -2.35 & 1.21 & 0.053 \\
& Intercept & -0.75 & 0.13 & $<0.001$ \\
& Illumination & 0.47 & 0.19 & 0.016 \\
\hline
\end{tabular}

0.96 and $P<0.001)$. We detected adult male ferrets more frequently on nights with greater moon illumination (Fig. 2). In contrast, for female ferrets, there was little evidence of an effect of moon illumination on spotlight detection $($ ratio $=3.77, \mathrm{df}=2, P=0.152$; Tables 3 and 4 ).

\section{Discussion}

In our study, spotlight detection of ferrets was more likely if the moon breached the horizon during a survey, suggesting ferrets are aboveground more often and are detected more easily via spotlight during moonlit nights (hypothesis 1). These results are consistent with a telemetry study in which ferrets were more active during moonlit nights (Biggins et al. 2011). Like southern lesser galagos (Galago moholi) that use moonlight for navigation on the ground between trees (Bearder et al. 2002), ferrets might use moonlight during aboveground 


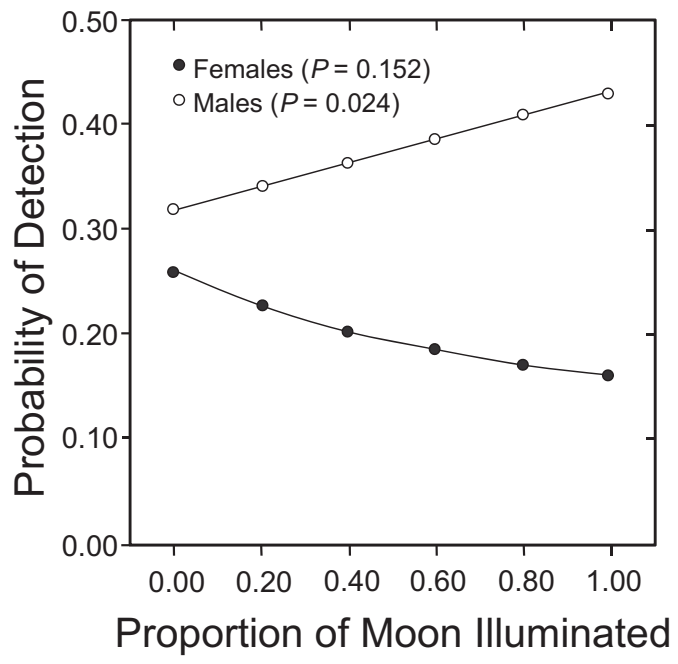

Fig. 2. Estimated linear and pseudothreshold $(\log [x+$ $0.50]+x)$ moon-illumination effects $(1.00=$ full moon $)$ from generalized linear mixed models describing the probability of detecting adult female or male black-footed ferrets (Mustela nigripes) via late-night, postbreeding spotlight surveys on 2 black-tailed prairie dog (Cynomys ludovicianus) colonies in the Conata Basin, South Dakota, 2005-2008. Estimated variances for the random intercepts were low; thus, we present fixed-effect population models for female and male ferrets from Table 4 . $P$ values were derived from deviance ratio tests that compared the most supported model for a sex to an intercept-only model for that sex (see Table 3).

navigation between openings to prairie dog burrows (Biggins 2000). Physical and behavioral characteristics of the ferret might reduce predation costs of activity under moonlight. For example, under moonlight, the ferret's buckskin and black pelage and black-tipped tail might aid in concealment (Verrill 1987) and predator confusion (Powell 1982), respectively, and the ferret's facemask can reduce light reflection and thus facilitate visual acuity (Ortolani 1999; but see Newman et al. 2005, Caro 2009, Stankowich et al. 2011). Also, ferrets spend the most time in areas where prairie dog burrow openings (i.e., refuge) are abundant (Biggins et al. 2006b, Livieri 2007, Jachowski et al. 2011, Eads et al. 2011a, 2011b).

In addition to the presence or absence of the moon above the horizon, the amount of illumination is important in spotlight surveys of ferrets (hypothesis 2). Biggins et al. (2011) did not detect a change in aboveground activity by ferrets with increasing moon illumination (see also Wei et al. 2002), suggesting the amount of moon illumination would not influence spotlight sur- veys. The Biggins et al. (2011) telemetry study was primarily conducted to compare behaviors of $M$. nigripes and the closely related Siberian polecat (M. eversmanni), and differences between sexes within these Mustela species were not investigated (Biggins et al. 2011). Our analyses suggested intersexual differences in spotlight detection relative to moon illumination. We located adult male ferrets most frequently during nights of bright moon illumination; perhaps bright moonlight facilitates aboveground movement more than dim moonlight. In contrast, our data failed to document a relationship between moon illumination and detection of adult female ferrets. Prey requirements of kits necessitate increased hunting by adult females relative to adult males with limited (or no) parental investment (Miller et al. 1996). In addition, adult females must transfer prey to kits (Hillman 1968) or kits to burrows containing prey (Hillman 1968, Paunovich and Forrest 1987, Jachowski 2007a), presumably increasing the females' need for aboveground activity relative to the more solitary activities of adult males. Such parental requirements might limit opportunities for response or mask responses of adult females to variation in moon illumination. For example, adult female ferrets with kits might be active during dark, dim, or bright nights to acquire prey for kits, to move kits among den sites, and to socialize with kits at den openings (thus masking an effect of moonlight), whereas adult males are removed from parental requirements that might mask response to moon illumination.

Ferret response to amount of moon illumination is a particularly difficult relationship to study because the proportion of the moon illuminated is correlated with (1) time of moonrise and (2) proportion of the night with illumination by the moon. For example, small proportions of moon illumination are associated with short periods of moonlight during the night (and they occur near dawn and dusk), creating confounded interpretations of the effects of temporal periods of night, moon brightness, and duration of moon illumination during night. The differing duration of availability of the moon at varying phases might influence our interpretation of preferences by the ferrets. For studies of moon illumination, however, varying availability might not affect evaluations of differences between groups of animals because availability can be assumed to equally influence both groups (e.g., 
ferrets vs. polecats in the Biggins et al. 2011 telemetry study discussed above and males vs. females in the present study). Nevertheless, changes in detection of ferrets, or changes in ferret activity that correlate with moon illumination values herein and elsewhere should be interpreted cautiously. Furthermore, telemetry data reflect amounts and types of aboveground activity (movement vs. stationary; e.g., one location per ferret per $15.58 \pm 0.35 \mathrm{~min}$, Biggins 2000), whereas our data reflect detection of ferrets aboveground via spotlight (interpreted as a proxy for activity). If intensive telemetry and spotlight data are collected in unison, and if additional measures are used to adjust for differing availability, additional insight might be gained into lunar influences on ferret activity, spotlight detection of ferrets, and general spotlight survey efficiency (costs and benefits of telemetry in Biggins et al. 2006c).

Biological requirements for ferrets differ among seasons and between sexes. For instance, during our study, adult female ferrets raised kits while adult males did not. Such differences might have implications for spotlight surveys (hypothesis 3). We located adult female ferrets most frequently in August. As late August and September approach, young ferrets approach adult size but are often still dependent on their mother for food (Biggins et al. 1993, Miller et al. 1996). Adult female ferrets might increase hunting efforts to provide prey for nearly independent offspring. In September-October, after the primary litter-rearing period, spotlight detection of adult females declined. We attribute this decline to 3 factors: (1) detection of adult females might be enhanced when spotlighters detect kits exhibiting increased aboveground activity in August (Paunovich and Forrest 1987). A group effect is indeed probable (Buckland et al. 2008); at times, we saw one or more kits, followed by detection of the associated mother. As kits become independent of their mother, their effect on detection of their mother is expected to diminish quickly. (2) Adult female ferrets likely reduced overall activity as their kits became independent and prey requirements declined (prey requirements discussed by Biggins et al. 1993). (3) Lastly, later in each field season, adult female ferrets might have exhibited more uniform activity throughout a night, rather than concentrating aboveground movements during early morning hours (01:00-03:00; Biggins et al. 1986). We concentrated surveys in late-night periods (midnight-06:00) and, consequently, could not investigate this hypothesis. Telemetry data suggest ferrets exhibit more uniform hourly activity in winter, and the early morning activity peak (01:00-03:00) becomes less pronounced (Biggins et al. 1986). Thus, later in the field season, we likely missed adult female ferrets that were active before we started our surveys.

We are unable to distinguish between changes in detection rates of adult female ferrets that might be due to care of young and changes in detection due to a group effect (i.e., detection of kits that assists in detection of their mother), as both would be expected to occur somewhat synchronously. Chronologically, adult females might increase hunting efforts from June to midAugust to feed developing kits, resulting in increased spotlight detection (Fig. 3A). By early July, as kits are weaned and begin to eat more prairie dog meat, adult females need to kill increasing numbers of prairie dogs, requiring more aboveground activity and, likely, more shifts among den sites, resulting in greater spotlight detection. Indeed, we most commonly observed adult females during August. However, we most commonly observed kits aboveground with their mothers in August, as well; therefore detection at that time should also be influenced by occurrence of ferrets in groups (Fig. 3B). The detection curve might be expected to reach its asymptote in late August and early September, given that the growing kits require more food and group detection effects become most pronounced (Fig. 3C). Thereafter detection might decline as kits become independent of their mother, adult females hunt less, and the litter-rearing and group effects decline (Fig. 3D). The group effect would seemingly persist until the last litter of kits separates (Fig. 3E). Although we have hypothesized plausible detection curves with and without the group effect (Fig. 3), we cannot envision a pragmatic means of evaluating the relative strengths of these effects. Nevertheless, these hypothetical detection curves help explain the advantages of curvilinear forms of time (month) used in our statistical analyses. The quadratic form of time in our first analysis, for example, had considerable explanatory power but remains an approximation. The relationship between time and detection is likely more complex than a simple parabola.

We detected adult male ferrets less frequently in July than in June, with increased 

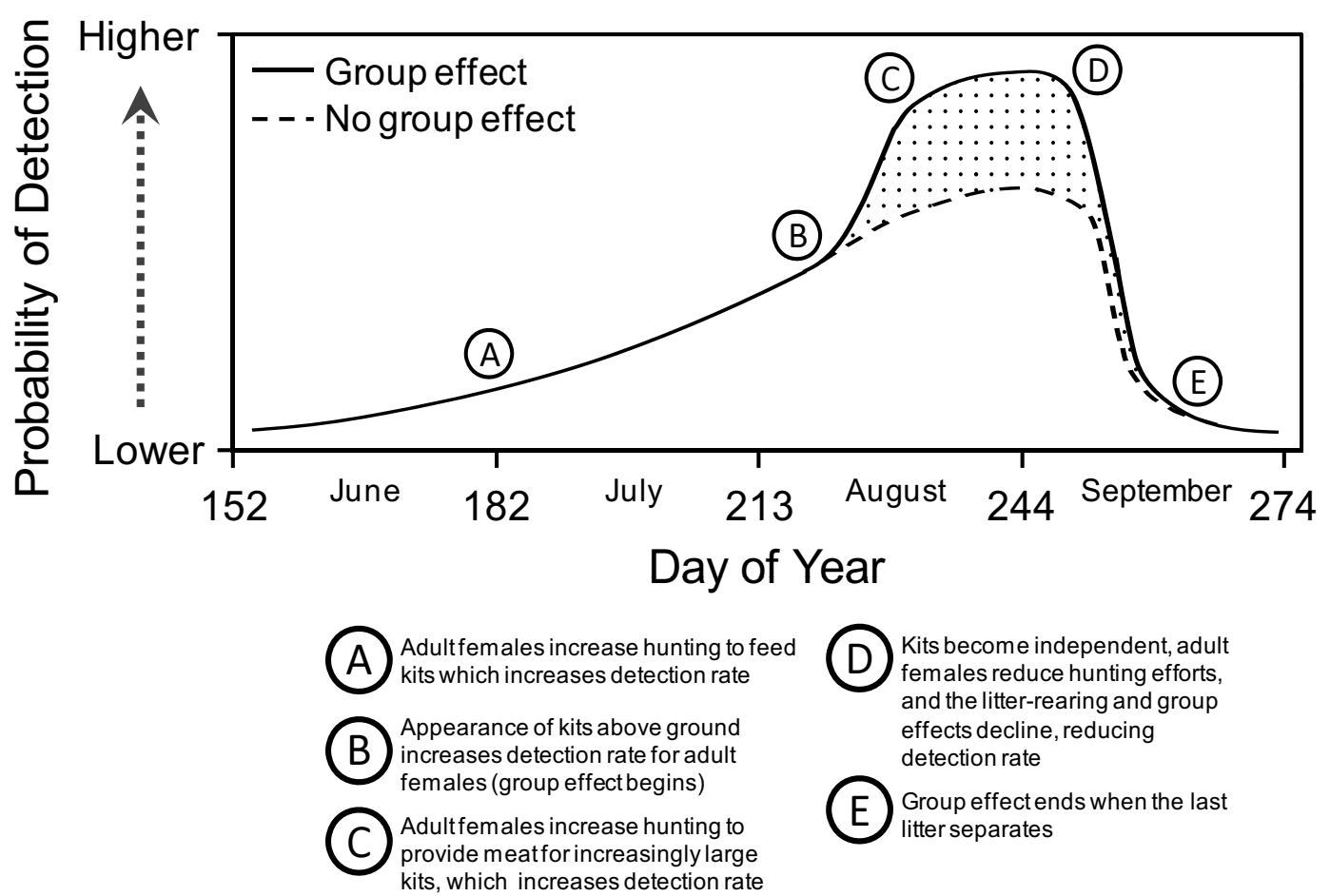

Fig. 3. Hypothetical curves for the probability of detecting adult female black-footed ferrets (Mustela nigripes) during the postbreeding season. Curves correspond to hypotheses for (1) detection of adult females with a group effect (i.e., increased detection of adult females due to detection of kits) and (2) detection of adult females without a group effect. These curves are described in more detail in the text.

detection thereafter. Adult male ferrets might increase activity in September-October to monitor activity areas of females (Sandell 1989), to establish or supplement scent marks (King and Powell 2007), and perhaps to monitor or exclude male ferrets, including kits (i.e., future competition for mates). Indeed, evidence of prior residency advantages in ferrets (Biggins et al. 2006b) and relatively low amounts of intrasexual space-use overlap (Livieri 2007, Jachowski et al. 2010, Fagerstone and Biggins 2011) suggest territorial behaviors. In addition, male ferrets might increase hunting efforts to gain mass before winter and the breeding season (February-March; Miller et al. 1996). However, costs of gain in mass (e.g., reduced speed and agility; King and Powell 2007) might create a trade-off. Additional factors (e.g., variation in temperature, prey behavior, or abundance and so forth) might contribute to monthly variation in spotlight detection of adult male and adult female ferrets and are deserving of future investigation.
Conservation and Management Implications

This study demonstrates that efforts to estimate sizes of ferret populations and to compare population estimates among sites would benefit from accounting for lunar and temporal influences on spotlight detection of ferrets. Although across-site standardization is complicated by intersite variation in climate, logistical constraints (e.g., money and numbers of surveyors), and physiographic features (e.g., rough vs. flat terrain), a generalized approach seems plausible. A recent spotlight-based method of estimating ferret population size (Shirley Basin, WY; Grenier et al. 2009), if useful at other sites, could provide a methodological template. As demonstrated herein, managers should continue to concentrate postbreeding surveys in AugustSeptember (Biggins et al. 1986, Fagerstone and Biggins 1986, Grenier 2008). At a finer scale, our results suggest that survey efforts should be focused when the moon is above the horizon during moonlit nights and, if survey time is 
limited, between 01:00 and 03:00 (Biggins et al. 1986, Clark et al. 1986).

\section{ACKNOWLEDGMENTS}

This study was made possible through State Wildlife Grant T35, study number 2435, provided by the South Dakota Department of Game, Fish and Parks. Funding and logistical support also were provided by the United States Fish and Wildlife Service, the United States Forest Service, the United States Geological Survey, Prairie Wildlife Research, the National Fish and Wildlife Foundation (Grant number 20060058-0000), the Denver Zoological Foundation, the Disney Centennial Refuge Scholarship, the Missouri Chapter of the Wildlife Society, and the University of Missouri. DAE was also supported by S. and D. Webb. We are grateful to T. Livieri and Prairie Wildlife Research, R. Jachowski, D. Hanson, and D. Marsh for logistical support. Thanks also to R. Gitzen, T. Bonnot, C. Hanson, and A. Turner for statistical support and productive discussions, and to J. Chipault, S. Grassel, J. Scholl, and 4 anonymous reviewers for constructive reviews of previous versions of this manuscript.

Any use of trade, product, or firm names is for descriptive purposes only and does not imply endorsement by the U.S. federal government.

\section{Literature Cited}

Bearder, S.K., K.A.I. NeKaris, And C.A. BuZZEll. 2002. Dangers in the dark: are some nocturnal primates afraid of the dark? Pages 21-40 in L.E. Miller, editor, Eat or be eaten: predator sensitive foraging among primates. Cambridge University Press, Cambridge, United Kingdom.

Biebouw, K., AND D.T. Blumstein. 2003. Tammar wallabies associate safety with higher levels of nocturnal illumination. Ethology, Ecology, and Evolution 15:159-172.

Biggins, D.E. 2000. Predation on black-footed ferrets (Mustela nigripes) and Siberian polecats (M. eversmanni): conservation and evolutionary implications. Doctoral dissertation, Colorado State University, Fort Collins, CO

Biggins, D.E., J.L. Godbey, M.R. Matchett, L.R. HaneBURY, T.M. LIVIERI, AND P.E. MARINARI. 2006a. Monitoring black-footed ferrets during reestablishment of free-ranging populations: discussion of alternative methods and recommended minimum standards. Pages 155-174 in J.E. Roelle, B.J. Miller, J.L. Godbey, and D.E. Biggins, editors, Recovery of the blackfooted ferret: progress and continuing challenges. U.S. Geological Survey Scientific Investigations Report 2005-5293.

Biggins, D.E., J.L. Godbey, M.R. Matchett, and T.M. LIVIERI. 2006b. Habitat preferences and intraspe- cific competition in black-footed ferrets. Pages 129-140 in J.E. Roelle, B.J. Miller, J.L. Godbey, and D.E. Biggins, editors, Recovery of the black-footed ferret: progress and continuing challenges. U.S. Geological Survey Scientific Investigations Report 20055293.

Biggins, D.E., J.L. Godbey, B.J. Miller, and L.R. HaneBURY. 2006c. Radio telemetry for black-footed ferret research and monitoring. Pages 173-190 in J.E. Roelle, B.J. Miller, J.L. Godbey, and D.E. Biggins, editors, Recovery of the black-footed ferret: progress and continuing challenges. U.S. Geological Survey Scientific Investigations Report 2005-5293.

Biggins, D.E., L.R. Hanebury, B.J. Miller, and R.A. PowELL. 2011. Black-footed ferrets and Siberian polecats as ecological surrogates and ecological equivalents. Journal of Mammalogy 92:710-720.

Biggins, D.E., B. Miller, L. Hanebury, R. Oakleaf, A. Farmer, R. Crete, and A. Dood. 1993. A technique for evaluating black-footed ferret habitat. Pages 73-78 in J. Oldemeyer, B. Miller, and R. Crete, editors, Management of prairie dog complexes for reintroduction of the black-footed ferret. U.S. Fish and Wildlife Service Biological Report 13.

Biggins, D.E., M.H. Schroeder, S.C. Forrest, and L. RiCHARDSON. 1986. Activity of radio-tagged blackfooted ferrets. Great Basin Naturalist Memoirs 8: 135-140.

Brown, J.S., B.P. Kotler, R.J. Smith, and W.O. Wirtz II. 1988. The effects of owl predation on the foraging behavior of heteromyid rodents. Oecologia 76: 408-415.

Buckland, S.T., D.R. Anderson, K.P. Burnham, J.L. LaAKe, D.L. Borchers, AND L. Thomas, editors. 2008. Advanced distance sampling: estimating abundance of biological populations. Oxford University Press, Oxford, United Kingdom.

BuRnhaM, K.P., AND D.R. ANDERSON. 2002. Model selection and multimodel inference: a practical informationtheoretic approach. 2nd edition. Springer-Verlag, New York, NY.

Campbell, T.M., III, D. Biggins, S. Forrest, and T.W. CLARK. 1985. Spotlighting as a method to locate and study black-footed ferrets. Pages 24.1-24.7 in S.H. Anderson and D.B. Inkley, editors, Proceedings of the Black-footed Ferret Workshop. Wyoming Game and Fish Department, Cheyenne, WY.

CARO, T. 2005. Antipredator defenses in birds and mammals. University of Chicago Press, Chicago, IL. 2009. Contrasting coloration in terrestrial mammals. Philosophical Transactions of the Royal Society B: Biological Sciences 364:537-548.

Clark, T.W., T.M. Campbell, M.H. Schroeder, and L. Richardson. 1984. Handbook of methods for locating black-footed ferrets. Wyoming Bureau of Land Management Wildlife Technical Bulletin Number 1, Cheyenne, WY.

Clark, T.W., L. Richardson, S.C. Forrest, D.E. Casey, AND T.M. CampbeLL. 1986. Descriptive ethology and activity patterns of black-footed ferrets. Great Basin Naturalist Memoirs 8:115-134.

EADS, D.A. 2009. Evaluation and development of blackfooted ferret resource selection models. Master's thesis, University of Missouri, Columbia, MO. 
Eads, D.A., J.J. Millspaugh, D.E. Biggins, D.S. Jachowski, AND T.M. LIVIERI. 2011a. Evaluation of a black-footed ferret resource utilization function model. Journal of Wildlife Management 75:1155-1163.

Eads, D.A., J.J. Millspaugh, D.E. Biggins, T.M. Livieri, AND D.S. JACHOWSKI. 2011b. Post-breeding resource selection by adult black-footed ferrets in the Conata Basin, South Dakota. Journal of Mammalogy 92:760-770

Fagerstone, K.A., AND D.E. Biggins. 1986. Summary of black-footed ferret and related research conducted by the Denver Wildlife Research Center. Internal report, 3 March 1986, U.S. Fish and Wildlife Service.

2011. Black-footed ferret areas of activity during late summer and early fall at Meeteetse, Wyoming. Journal of Mammalogy 92:705-709.

Fagerstone, K.A., And B.E. Johns. 1987. Transponders as permanent identification markers for domestic ferrets, black-footed ferrets, and other wildlife. Journal of Wildlife Management 51:294-297.

Forrest, S.C., D.E. Biggins, L. Richardson, T.W. Clark, T.M. Campbell, K.A. Fagerstone, and E.T. Thorne. 1988. Population attributes for the black-footed ferret (Mustela nigripes) at Meeteetse, Wyoming, 19811985. Journal of Mammalogy 69:261-273.

Franklin, A.B., D.R. Anderson, R.J. Gutiérrez, and K.P. Burnham. 2000. Climate, habitat quality, and fitness in Northern Spotted Owl populations in northwestern California. Ecological Monographs 70:539-590.

Gelman, A., And J. Hill. 2007. Data analysis using regression and multilevel/hierarchical models. Cambridge University Press, New York, NY.

Grenier, M.B. 2008. Population biology of the black-footed ferret reintroduced into Shirley Basin, Wyoming. Master's thesis, University of Wyoming, Laramie, WY.

Grenier, M.B., S.W. Buskirk, AND R. Anderson-Sprecher. 2009. Population indices versus correlated density estimates of black-footed ferret abundance. Journal of Wildlife Management 73:669-676.

Hillman, C.N. 1968. Life history and ecology of the blackfooted ferret in the wild. Master's thesis, Wildlife Management Department, South Dakota State University, Brookings, SD.

JACHOWSKI, D.S. 2007a. Notes on black-footed ferret detectability and behavior. Prairie Naturalist 39:99-104. 2007b. Resource selection by black-footed ferrets in relation to the spatial distribution of prairie dogs. Master's thesis, Department of Fisheries and Wildlife Sciences, University of Missouri, Columbia, MO.

Jachowski, D.S., J.J. Millspaugh, D.E. Biggins, T.M. Livieri, and M.R. MatchetT. 2010. Home-range size and spatial organization of black-footed ferrets Mustela nigripes in South Dakota, USA. Wildlife Biology 16:1-11.

Jachowski, D.S., J.J. Millspaugh, D.E. Biggins, T.M. Livieri, M.R. Matchett, and C.D. Rittenhouse. 2011. Resource selection by black-footed ferrets in South Dakota and Montana. Natural Areas Journal 31:218-225.

KInG, C.M., AND R.A. PowelL. 2007. The natural history of weasels and stoats: ecology, behavior, and management. 2nd edition. Oxford University Press, Oxford United Kingdom.
KotLER, B.P. 1984. Risk of predation and the structure of desert rodent communities. Ecology 65:689-701.

Kotler, B.P., J.S. Brown, And O. Hasson. 1991. Factors affecting gerbil foraging behavior and rates of owl predation. Ecology 72:2249-2260.

Lima, S.L., AND L.M. DiLl. 1990. Behavioral decisions made under the risk of predation: a review and prospectus. Canadian Journal of Zoology 68:619-640.

LiVIERI, T.M. 2006. Ten-year history of the Conata Basin black-footed ferret population: 1996-2005. Report, Prairie Wildlife Research, Wall, SD.

2007. Black-footed ferret spatial use of prairie dog colonies in South Dakota. Master's thesis, University of Wisconsin, Stevens Point, WI.

LOCKARD, R.B., AND D.H. OwINGS. 1974. Seasonal variation in moonlight avoidance by bannertail kangaroo rats. Journal of Mammalogy 55:189-193.

MCCullagh, P., AND J.A. NELDER. 1989. Generalized linear models. 2nd edition. Chapman and Hall, New York, NY.

Miller, B., R.P. Reading, and S.C. Forrest. 1996. Prairie night: black-footed ferrets and the recovery of endangered species. Smithsonian Institution Press, Washington, DC.

Newman, C., C.D. Buesching, and J.O. WolfF. 2005. The function of facial masks in "midguild" carnivores. Oikos 108:623-633.

Ortolani, A. 1999. Spots, stripes, tail tips and dark eyes: predicting the function of carnivore colour patterns using the comparative method. Biological Journal of the Linnean Society 67:433-476.

PaunOVICH, R., AND S.C. ForRest. 1987. Activity of a wild black-footed ferret litter. Prairie Naturalist 19:159-162.

Powell, R.A. 1982. Evolution of black-tipped tails in weasels: predator confusion. American Naturalist 119: 126-131.

Prugh, L., AND J. Brashares. 2010. Basking in the moonlight? Effect of illumination on capture success of the endangered giant kangaroo rat. Journal of Mammalogy 91:1205-1212

R Development Core Team. 2010. R: a language and environment for statistical computing. $\mathrm{R}$ Foundation for Statistical Computing, Vienna, Austria. ISBN 3-90005107-0. Available from: http://www.R-project.org

SANDELL, M. 1989. The mating tactics and spacing patterns of solitary carnivores. Pages 164-182 in J.L. Gittleman, editor, Carnivore behavior, ecology, and evolution. Volume 1. Cornell University Press, Ithaca, NY.

Stankowich, T., T. CARO, AND M. Cox. 2011. Bold coloration and the evolution of aposematism in terrestrial carnivores. Evolution 65:3090-3099.

Topping, M.G., J.S. Millar, and J.A. Goddard. 1999. The effects of moonlight on nocturnal activity in bushytailed wood rats (Neotoma cinerea). Canadian Journal of Zoology 77:480-485.

U.S. Fish and Wildlife Service. 2006. Draft recovery plan for the black-footed ferret (Mustela nigripes). U.S. Fish and Wildlife Service, Denver, CO.

VERRILL, A.E. 1987. Nocturnal protective coloration of mammals, birds, fishes, insects, etc. American Naturalist 31:99-103.

WeI, W.H., W.Y. Zhou, and N.C. FAN. 2002. The influence of moonlight on and light intensity on activity of polecats (Mustela eversmanni). Acta Theriologica Sinica 22:179-186. 
YlÖNEN, H., AND J.S. BRown. 2007. Fear and foraging, breeding, and sociality of rodents. Pages 328-341 in J.O. Wolff and P.W. Sherman, editors, Rodent societies: an ecological and evolutionary perspective. University of Chicago Press, Chicago, IL.

ZuUr, A.F., E.N. Ieno, N.J. WalKer, A.A. Saveliev, and G.M. Sмiтh. 2009. Mixed effects models and exten- sions in ecology with R. Springer Science + Business Media, New York, NY

Received 18 April 2011

Accepted 30 January 2012 